\title{
Ю.А. Ишутина
}

\section{К ВОПРОСУ ОБ УПРАВЛЕНИИ ПРОЦЕССАМИ ГЛОБАЛИЗАЦИИ В КНР И КР (ТАЙВАНЬ)}

\begin{abstract}
Процессы формирования и репрезентация национальной идентичности в КНР и на Тайване имеют ряд специфических особенностей, проистекающих из повседневности континентальных и островных китайцев. Вследствие глобальной разниць между условиями существования этих двух частей китайского общества возникают различнье реакции в виде локализаций глобальной культуры и регионального подхода к новой реальности, что приводит к постепенным изменениям в процессе эволюиии национального самосознания китайцев и тайваньцев.

Ключевые слова: глобализированная культура, национальная идентичность, Китайская Республика (Тайвань), управляемая глобализация, язык интеграции.
\end{abstract}

Сложные и стремительные процессы глобализации способствуют интеграции различных регионов мира, делая его ощутимо ближе, ускоряя темп жизни включенных в них обществ, задавая особый ритм функционирования социальной, культурной, экономической сферы деятельности каждого участника. Последствия таких взаимодействий возможны в виде замещения местной культуры глобальной, симбиоза культур без заметного слияния, синтеза культур или полного отрицания в результате мощной локальной реакции в зависимости от интенсивности взаимодействия и степени податливости местной культуры [1].

Глобализированная культура на первый взгляд должна быть гомогенной, но по прошествии времени появляются новые гетерогенные формы, так как при взаимодействии включаются внутренние процессы сохранения собственных культурных отличий контактируемых сообществ. Страны, активно осуществляющие интеграцию в мировое сообщество, способны группироваться вокруг стержневых региональных государств подобно тому, как Корея, Тайвань, Сингапур, Малайзия и др. традиционно ориентируются в своем развитии на самую мощную державу региона - Китай, хотя «рекомендацию» к приобщению к глобализированной культуре получают от Японии, успешно прошедшей путь модернизации гораздо раньше.

Глобализация считается высшей стадией модернизации и, как правило, проявляется в четырех основных аспектах жизни общества, удачно определенных П. Бергером и С. Хантингтоном как давосская культура, клубная культура интеллигенциии, массовая культура и массовые движения того или иного типа $[1,2]$. Культурная глобализация наиболее явственно проявляется на уровне повседневности, и от этого ощущается индивидуумом наиболее чувствительно, а для исследователя открываются широкие возможности изучения процессов принятия глобальной культуры и реакции местных культур. Специфическая черта современного состояния процесса заключается в том, что «местные культуры продолжают производить... внезапно появляющиеся 
социальные организмы, принимают новые адаптивные формы, чтобы выжить и произвести себя» [1]. Потребителю становится не столь важно, откуда родом предлагаемый ему продукт глобализации, на уровне повседневности для него гораздо важнее приспособить его под свои бытовые потребности и духовные запросы, причем результат должен быть ожидаем в рамках реальных последствий. Так происходит локализация продуктов глобализации, его адаптация под местные условия. Небезынтересно проследить, как реагируют на феномен культурной глобализации на современном этапе народы КНР и КР (Тайвань), по сути представляющие собой два варианта альтернативного развития одного общества разной политической формации, имеющего в основе одинаковую исходную базу конфуцианской идеологии, неоднородный этнический состав, общую историю и различную национальную идентичность.

Гипотеза исследования заключается в том, что вследствие разницы, которую можно проследить во многих аспектах жизни, начиная от масштабности

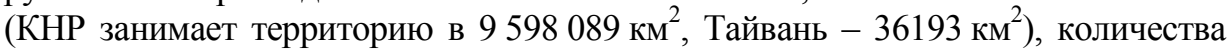
народонаселения (в КНР к концу 2018 г. будут проживать 1401295763 человек, а на Тайване - 23,57 млн граждан), разности политических систем, символической соположенности (континентальный Китай, ощущаемый как священная ойкумена, и островной Тайвань, находящийся на периферии китайского мира), возникают различные реакции в виде локализаций глобальной культуры и регионального подхода к новой реальности, что приводит к постепенным изменениям в процессе эволюции национального самосознания китайцев и тайваньцев.

Общее восприятие феномена культурной глобализации в китайском и тайваньском обществах, в разное время прошедших период изолированности и включенности в мировое сообщество, а в настоящее время активно определяющих свою позицию по отношению к другим участникам процесса, можно охарактеризовать как положительное. Нюансы возникают в формулировке степени активности (возможно, степени открытости миру и готовности к процессу). На наш взгляд, наиболее показательным примером является формулировка лозунга, принятого в континентальном Китае: «中国走向世界》 Zhōngguó zŏuxiàng shìjiè («Китай идет навстречу миру»), в то время как Тайвань транслирует желание «принадлежать миру» (台湾属于世界Táiwăn shŭyú shìjiè) [3]. В данном случае мы склонны трактовать посыл тайваньского народа как стремление считаться частью мирового сообщества и разделять его общую судьбу, тогда как народы КНР готовы познать феномен глобальной культуры, сохраняя ощущение своей обособленности. В тайваньском случае «принадлежность» ощущается как сопричастность, что является мощным интегрирующим фактором, так как практически в каждой из основных национальных идей прослеживается мотив объединения по принципу «общей судьбы» [4].

Если рассматривать приобщение обеих частей китайского общества, разделенных проливом, к массовой культуре как одному из аспектов глобализации, то наблюдается схожее явление четкого отделения «национальной» принадлежности продукта глобальной культуры. Ни китайцы, ни тайваньцы не склонны ассоциировать появление ресторанов быстрого питания (KFC, Масdonald's), увлечение здоровым образом жизни (фитнес, питание и т.п.), стремление к комфортному существованию и обладание ультрасовременны- 
ми гаджетами исключительно с западной (американской) культурой. Все перечисленное принимается как данность, примета современной жизни модернизированного, но не вестернизированного сообщества. Повсеместно можно наблюдать примеры успешной локализации, как-то: включение в меню KFC, работающего на территории КНР, целого списка закусок, приготовленных в лучших традициях китайской кухни. Например, наиболее покупаемый товар в KFC - позиция «老北京» lăo Běijīng, буквально «Вкус старого Пекина» (в виде завернутых в лаваш тонко порезанных кусочков утиного мяса с соусом, как это делается в знаменитом ресторане пекинской утки «Цюань цзюй дэ», 《全聚德》), или уличного деликатеса 《日式海鲜寺》 rìshì hăixiān yù (фаршированного морепродуктами плода таро под соусом с добавлением японской водоросли даси), продающегося на Ночном рынке близ станции метро 劍潭 Цзяньтань в Тайбэе.

На социентальном уровне западные культурные ценности восприняты (вряд ли будут приняты полностью и до конца), локализированы, переработаны, осмыслены и по старой доброй традиции соотнесены с фактами и прецедентными событиями, имевшими место в высокой китайской истории и самых истоках конфуцианства. Ввиду того, что китайская культура может оперировать целыми тысячелетиями, достижения западной духовной и материальной культуры воспринимаются как нечто молодое, специфическое, но еще не прошедшее проверку столь длительным временем. Приобщение к продукту глобальной культуры происходит на уровне пробы на вкус, цвет, комфортность, является чем-то вроде социального ритуального действия и остается на уровне познавательной деятельности и потребления.

И в Китае, и на Тайване формирование глобальной массовой культуры четко прослеживается как в классовых, так и возрастных границах: молодежь, особенно городская, активнее включает в свой мир ценностей символы американской и / или корейской (на северо-западе и в центральных регионах КНР) и западной и / или японской культуры (на юго-восточном побережье и на Тайване). Пожилая часть населения, сельские жители и рабочие северовостока и центральных провинций континентального Китая вряд ли могут пополнить ряды течения 哈日族Hā rì zú, благосклонно реагирующих на все японское и обожающих абсолютно все, что порождает японская массовая культура. Эта часть населения чувствительна к японцам по совсем другой причине - горькой памяти Мукденского инцидента 18 сентября 1931 г., печальную годовщину которого весь китайский северо-восток ежегодно встречает воем сирен.

Вследствие того, что память о жертвах японской агрессии крепка и бережно хранима, массовая культура в континентальном Китае не так японизирована, как на Тайване, хотя продукт американского и европейского образа жизни успешно «переупаковывается»: в китайской мечте 中国梦想 Zhōngguó mĕngxiàng четко прослеживаются черты американской мечты (да и общечеловеческой тоже). Для жителей Тайваня все же ближе адаптированная к местным условиям японская мечта, ежедневно репрезентируемая с экрана японских каналов с иероглифическим подстрочником на 国语 guóyŭ (аналоге 普通话pǔtōnghuà), повторенная во множестве культурных объектов и гармонично внедренная в тайваньскую повседневность. Тем не менее глубоких 
культурных изменений в тайваньском обществе не произошло, китайская культура в условиях глобализации дает новые точки роста для возрождения и популяризации традиционного образа жизни.

Глобальная массовая культура привлекательна для той части китайского населения КНР и Тайваня, которая, кроме финансовых возможностей к приобщению, обладает информационным доступом к рекомендуемым продуктам глобализации. В КНР правительство осуществляет процесс управляемой глобализации, контролируя с разной степенью все четыре сферы ее проявления. Масштабы академической мобильности молодых китайских яппи в форме обучения за рубежом пока невелики, так как осуществляются при финансовой поддержке семейного клана в большей степени, и в меньшей - за счет использования средств различных зарубежных общественных организаций, в то время как общеобразовательная школа КНР находится под жестким контролем властей, определяющим, как и в каком объеме, в какой подаче юный гражданин КНР познает мир. Так, в учебнике родного языка в младшем звене китайской школы наблюдается гармоничное соотношение текстов китайской конфуцианской догматики, высокой классики (легкие в восприятии и лаконичные образцы танской и сунской поэзии), адаптированных текстов русской (советской) и европейской детской литературы в первом классе. Второй год обучения характеризуется увеличением доли китайских текстов конфуцианской тематики до 45 процентов, для наглядности сопоставленных с рассказами о Ленине (выдержанных в теплых дружеских тонах марксистсколенинской философии), и вводится обширный пласт текстов, повествующих об американском (европейском) образе жизни и мышлении. Третий год обучения систематизирует знания о китайских мифах (мифический этап китайской истории) и обращает взор юного исследователя от священной ойкумены к ее окраинам, маргинальным с точки зрения классического китайца территориям - Тайваню и Гонконгу, современное эмоциональное состояние которых, однако, описывается как «тоскующее», «стремящееся вернуться к корням». Для простоты восприятия акцент делается на «малом возрасте» Тайваня-сына (400 лет) и «высоком возрасте» Китая-матери (5 000 лет). Детям ничего не сообщается об «азиатском сиротстве» Тайваня, что стало фирменной карточкой и прекрасной легендой, удачно реализовавшей притязания тайваньцев на признание у определенной части мирового сообщества, но настойчиво привносится мотив необходимости помочь маленькому Тайваню вернуться к большой Родине, так как он скучает и сдерживается насильно. В качестве счастливого примера приводится история маленького Гонконга, получившего от большой китайской семьи по возвращении чудесный подарок в виде позолоченного цветка баухинии (фото в плохом качестве). На четвертом году тексты усложняются не только в синтаксисе, лексике и грамматике, но и тематически - появляются истории о героях корейской войны, например Хуан Цзигуане $[5,6]$. Если рассмотреть программу с точки зрения методологии обучения родному языку, истории, философии и т.П., то учебники представляют собой адаптированный и модернизированный вариант классического обучения с его всеобъемлющим подходом; что касается доступности информации о внешнем мире, то она дается небольшими порциями для ознакомления с нравами и традициями других народов в духе формирования стереотипов о западных и советских людях. Формируется ощущение китай- 
ского школьника о своем положении в геополитическом пространстве как в центральной точке мира, где природа гармонична и сбалансирована, человек добродетелен, вектор общественно-политического развития задан правильно. Удаленные от центра территории (Тайвань, Гонконг) - китайские, но периферийные, нуждающиеся в приобщении к Большому Китаю. Здесь прослеживается четкая идея единения и семейной общности, что нашло отражение в китайской национальной идее единения 才结tuánjié.

Восприятие тайваньского школьника несколько иное уже в силу того, что Тайвань - это остров, значит, периферия оказывается не по его абрису, а как раз в центре острова. Тайвань позиционируется как неотъемлемая часть мировой культуры и мирового пространства; тайваньская повседневность сжата ввиду небольшой островной территории, но обустроена, продумана до мелочей и привлекательна. Притягательность Тайваня начинается с природы и ландшафта, благодаря чему остров на старых мореходных картах носит название Формоза (Прекрасный), проявляется в спокойном и отзывчивом характере его жителей.

В традиционном понимании китаец сосуществует с природой в гармонии, и тайваньский китаец стремится ее сохранять, что выливается в деятельность социальных глобалистических движений типа «Друзья природы», «Глобальная деревня», «Панды» и т.п. Континентальный Китай также выказывает озабоченность состоянием окружающей среды, подкрепляя социальную рекламу авторитетом участвующих в ней тематических персонажей: так, Яо Мин, начинавший свою баскетбольную карьеру в «Шанхайских акулах», призывает отказаться от деликатесного супа из акульих плавников, резюмируя - нет спроса, нет предложения, нет убийства (акул). Джеки Чан, ощущающий себя китайцем из Гонконга, так называемого «малого азиатского тигра», выступает в защиту реальных тигров и т.д.

Тайваньцы прививают любовь к окружающей среде с детства, так, в учебнике родного языка за третий год обучения содержится не менее $35 \%$ учебных текстов под рубрикой 感受大自然 gănshōu dàzìrán «Почувствуй природу», в которых вводится классическое понимание красоты природы с призывом оберегать ее, наслаждаясь. Тексты носят говорящие названия: «Мелодия полей и огородов», «Записки о прогулках близ озера», «Школа барсука и университет белки-летяги» и т.п. В отличие от текстов подобной тематики, размещаемых в учебниках континентального Китая, изобилующих пышными определениями из классического языка и изящными сентенциями из высокой поэзии, скорее воспевающими природу как естественные декорации бытия, тайваньские тексты, написанные на государственном языке, скорее напоминают рассказы К.Г. Паустовского о поведении животных и красотах родной природы [7].

Включение рассказов из китайской древней литературы, например позднего сяошо «Яньский наследник Дань», дает подрастающему тайваньцу правильную установку на базовые элементы культурного поведения, вводит понятия долга, чести, преданности, реализует его ожидания на уровне повседневности, демонстрируя роль ритуала, например, в эпизоде отмщения героем Цзин Кэ за слабого (яньского принца крови Даня) более сильному обидчику (Циньскому правителю). 
Тексты конфуцианской направленности (45\%) перемежаются с описательными эссе, носящими характер наблюдений за повседневностью европейцев, американцев (система взаимоотношений, «символических обменов» между мужчинами и женщинами; родителями и детьми (семья и сепарация); молодыми и стариками; здоровыми и больными; «нормальными» и маргиналами; богатыми и бедными; социальной верхушкой и «простым народом» $(12 \%))$. Наполнение учебного текстового материала создает ощущение включения тайваньского школьника в мировую информационную систему, и даже предлагается средство для познания глобального мира - подробный материал об интернет-пространстве, а также о поисковых системах. Так, работе компании Google, еe продукту и, в частности, одноименной поисковой системе посвящен целый раздел в учебнике ( $8 \%)$.

К слову, в континентальном Китае эта система заблокирована; интернетпространство представляет собой Интранет, что свидетельствует о самом решительном намерении властей КНР контролировать процессы глобализации. Было бы неправильным считать, что ограничивается доступ к информации: она отфильтрована, выверена на предмет соответствия стратегическим интересам КНР и представлена не только в собственных поисковых системах, но и мощных наукометрических базах (CNKI, SCI, AHCI, CSSCI) [8].

Характер процессов глобализации в КНР и КР (Тайвань) вполне укладывается в парадигму, определенную Э. Гидденсом: «...всемирные социальные отношения интенсифицированы, отдаленные районы связаны друг с другом в том смысле, что местные происшествия отражают события, происходящие за много миль от них и наоборот» [1]. Однако эффект от взаимодействия сдерживается на уровне отражения, но не потрясения: при масштабности КНР это опасно и непредсказуемо. Национальная идентичность реализуется на уровне повседневности, и на этом же уровне проходят на прочность любые национальные идеи и символы, спущенные сверху, а для укоренения национального сознания тщательно подобранный материал предлагается к изучению и освоению в доступной форме учебника на родном языке.

Таким образом, мы наблюдаем в действии эволюцию образования современного типа, начавшегося с так называемого «печатного капитализма», когда, распространяя одни и те же учебники, книги, газеты и идеи на «языке интеграции», возможно было эффективно создавать стройную систему национальных идентичностей у «читающего поколения» того или иного народа, внедрять дискурс «картографирования, переписи и истории», позволяющий в гомогенном пустом времени и пространстве «вообразить» типологизированные серийные народы, проживающие на строго зафиксированных и отграниченных «национальных территориях», обладающих или стремящихся к обладанию «национальным самосознанием» [9].

К привычным средствам формирования национальной идентичности добавляются возникшие благодаря стремительным глобализационным процессам новые информационные медийные каналы, эффективность и скорость воздействия которых многократно превосходят имевшиеся ранее рычаги формирования идентичностей. Это значит, что правящей власти приходится осуществлять контроль за секторами глобального культурного рынка, собственными СМИ, издательской и общеобразовательной деятельностью, сферой интеллектуального развития и общественными движениями. На совре- 
менном этапе не делается акцент на контроле за массовой культурой, так как она помогает создать иллюзию общего процветания и достатка, а управление культурой деловой элиты не столь актуально, так как она пока еще очень мала как в КНР, так и на Тайване.

\section{Литература}

1. Многоликая глобализация / под ред. П. Бергера и С. Хантингтона. М. : Аспект Пресс, 2004. 379 c.

2. Хантингтон С. Столкновение цивилизаций. М. : АСТ : Астрель, 2011. 571 с.

3. Сюэ Хуаюань. Ранние исследования Чжан Цзюньциня по вопросам государственного самосознания // Эху. 2009. № 1. С. 44-50.

4. Ли Дэнхуэй. Позиция Тайваня / Ли Дэнхуэй. М., 2000. 272 с.

5. 语文。四年级上册。= Юй вэнь. Учебник родного языка. 4-й год обучения, первая часть. Харбин : Народное просвещение, 2008. 166 с.

6. 语文。四年级下册。= Юй вэнь. Учебник родного языка. 4-й год обучения, вторая часть. Харбин : Народное просвещение, 2008. 187 с.

7. 康轩小学电子书。六年级下册。APP = Электронный учебник младшей школы Кан Сюань. 6 год обучения, вторая часть. Тайбэй, 107 год основания КР (2018).

8. 王立。科学计量学高级教程。北京:科技文献出版社,二零一零。= Ван Ли. Кэсюэ цзилян сюэгаоцзи цзяочэн. Ван Ли. Высший курс наукометрии. Пекин : Изд-во Общества научнотехнической документации, 2010.

9. Андерсон Б. Воображаемые сообщества. Размышления об истоках и распространении национализма. М.: КАНОН-пресс-Ц, Кучково поле, 2001. 288 с.

Yuliya A. Ishutina, Eastern Institute - School of Regional and International studies of Far Eastern Federal University (Vladivostok, Russian Federation).

E-mail: ishutina.yuliya.74@mail.ru

Vestnik Tomskogo gosudarstvennogo universiteta. Kul'turologiya i iskusstvovedeniye - Tomsk State University Journal of Cultural Studies and Art History, 2019, 34, pp. 36-43.

DOI: $10.17223 / 2220836 / 34 / 3$

THE WAYS OF REGULATION OF GLOBALIZATION IN PRC@CR (TAIWAN)

Keywords: globalized culture; national identity; Chinese Republic (Taiwan); regulated globalization; integration means.

The general perception of the phenomenon of cultural globalization in Chinese and Taiwanese societies, at different times past a period of isolation and inclusion in the world community, and now actively defining its position in relation to other participants in the process, can be described as positive. Nuances arise in the formulation of the degree of activity (perhaps the degree of readiness for openness to the world).

The purpose of our study is to determine the specificity of the processes of globalization in continental and island China, based on materials from Chinese journalism. The object of study is the modernization of Chinese society, the subject is the participation of the state apparatus in regulating the extent of the impact of globalization on all spheres of life in Chinese society. In the materials of the Chinese press that we studied on this issue, we can clearly see two trends that determine the nature of the globalization processes of both parts of the Chinese nation. In the materials of the Chinese press that we studied on this issue, we can clearly see two trends that determine the nature of the globalization processes of both parts of the Chinese nation.

In our opinion, the most illustrative example is the slogan adopted in mainland China: “中国 走向 世界” Zhōngguó zŏuxiàng shìjiè (“China goes to meet the world”), while Taiwan broadcasts the desire to "belong to the world" (台湾 属于世界 Táiwăn shŭyú shìjiè). In this case, we interpret the message of the Taiwanese people as a desire to be considered as a part of the world community and share its common destiny, while the people of China are ready to learn the phenomenon of global culture while maintaining a sense of their own isolation. In the Taiwanese case, "belonging" is felt as ownership, which is a powerful integrating factor, since practically in each of the main national ideas, the unification on the principle of "common destiny". the societal level, Western cultural values are perceived (not accepted ), localized, reworked, comprehended and, according to good old traditions, 
correlated with facts and precedent events that took place in high Chinese history and the very origins of Confucianism. In view of the fact that Chinese culture can operate for many thousand years, the achievements of Western spiritual and material culture are perceived as something young, specific, but not accepted yet.

In both China and Taiwan, the formation of a global mass culture can be clearly seen both in class and age boundaries: young people, especially urban ones, actively include the symbols of American and / or Korean (in the north-west and central regions of the PRC) in their world of values, and Western and / or Japanese culture, (on the south-east coast and in Taiwan). The elderly, the villagers and workers of the northeast and central provinces of mainland China are unlikely to join the 哈日 族 Hārì zú current, favorably reacting to everything Japanese and adoring absolutely everything that the Japanese mass culture engenders

\section{References}

1. Berger, P. \& Huntington, S. (eds) (2004) Mnogolikaya globalizatsiya [Many Globalizations]. Translated from English by V.V. Sapov. Moscow: Aspekt Press.

2. Huntington, S. (2011) Stolknovenie tsivilizatsiy [The Clash of Civilizations and the Remaking of World Order]. Translated from English. Moscow: AST: Astrel'.

3. Xue Huayuan. (2009) Rannie issledovaniya Chzhan Tszyun'tsinya po voprosam gosudarstvennogo samosoznaniya [Zhang Junqin's early research on state identity]. Ekhu. 1. pp. 44-50.

4. Lee Denghui. (2000) Pozitsiya Tayvanya [Taiwan's Stance]. Moscow.

5. Yu Wen. (2008a) Uchebnik rodnogo yazyka. Chetvertiy god obucheniya [Textbook of the Native Language. Year 4]. Part 1. Kharbin: Narodnoe prosveshchenie.

6. Yu Wen. (2008b) Uchebnik rodnogo yazyka. Chetvertiy god obucheniya [Textbook of the Native Language. Year 4]. Part 2. Kharbin: Narodnoe prosveshchenie.

7. APP. (2018) Elektronnyy uchebnik mladshey shkoly Kan Syuan'. 6 god obucheniya [Electronic Textbook of Kang Xuan Elementary School. Year 6]. Part 2. Taipei: [s.n.].

8. Wang Li. (2010) Vysshiy kurs naukometrii [Higher course of scientometrics]. Beijing: Obshchestvo nauchno-tekhnicheskoy dokumentatsii.

9. Anderson, B. (2001) Voobrazhaemye soobshchestva. Razmyshleniya ob istokakh i rasprostranenii natsionalizma [Imaginary Communities. Reflections on the origins and spread of nationalism]. Translated from English. Moscow: KANON-press-Ts, Kuchkovo pole. 